\title{
What's Your Pleasure? Exploring the Predictors of Leisure Reading for Fiction and Nonfiction
}

Sandra Martin-Chang ${ }^{1}$, Stephanie Kozak ${ }^{1}$, Kyle C. Levesque ${ }^{2}$, Navona Calarco ${ }^{3}$, and Raymond A. Mar ${ }^{4}$

${ }^{1}$ Department of Education, Concordia University

${ }^{2}$ Department of Psychology and Neuroscience, Dalhousie University

${ }^{3}$ Centre for Addiction and Mental Health, Toronto, Ontario, Canada

${ }^{4}$ Department of Psychology, York University

\begin{abstract}
Author Note
Sandra Martin-Chang (D) https://orcid.org/0000-0003-4278-5179

Stephanie Kozak (D) https://orcid.org/0000-0001-7258-9078

Kyle C. Levesque (iD https://orcid.org/0000-0002-2506-3724

Navona Calarco (iD https://orcid.org/0000-0002-4391-0472

Raymond A. Mar (iD https://orcid.org/0000-0002-5307-7031

The authors have no conflicts of interest to disclose.

Correspondence concerning this article should be addressed to Professor Sandra MartinChang, Department of Education, Concordia University, 1455 De Maisonneuve Boulevard West, Montreal, Quebec, Canada, H3G 1M8. Email: s.martin-chang@concordia.ca
\end{abstract}




\begin{abstract}
Leisure reading is associated with several important educational and cognitive benefits, and yet fewer and fewer young adults are reading in their free time. To better study what drives leisure reading in undergraduates, we developed the Predictors of Leisure Reading (PoLR) scale. The PoLR investigates key predictors of leisure reading, namely reading motivations, obstacles, attitudes, and interests. We examined the PoLR's ability to predict language skills in 200 undergraduates, both directly and indirectly via exposure to fiction and nonfiction texts. Language skills were measured with a diverse battery of tasks, including items from two sections of the Scholastic Aptitude Test. We found that greater intrinsic reading enjoyment predicts better verbal abilities, and this was often explained via exposure to fiction rather than nonfiction. In contrast, participants who reported reading due to extrinsic pressures typically had weaker verbal abilities, often explained by stronger associations with nonfiction. This pattern was observed across the raw correlations and in a series of path analyses. In sum, it was 'reading enjoyment' and 'identifying as a reader' that uniquely predicted better verbal abilities in our undergraduate sample. The importance of these findings are discussed in relation to fostering intrinsic reading enjoyment throughout the various stages of formal education.

Keywords: intrinsic motivation, leisure reading, print exposure, reading fiction, reading motivation
\end{abstract}




\section{What's Your Pleasure? Exploring the Predictors of Leisure Reading for Fiction and Nonfiction}

Among the many benefits associated with leisure reading, perhaps none are more important than the advantages it affords to language and literacy. In light of the fact that voracious readers demonstrate superior reading and verbal abilities (e.g., Cunningham et al., 2001; Martin-Chang \& Gould, 2008; Stanovich et al., 1996), it is essential to understand what motivates or deters people from reading in their spare time. This question has been studied predominantly with children (e.g., Kavanagh, 2019; Stutz et al., 2016), however, young adults are entering a stage of life in which reading for pleasure becomes more voluntary and selfdirected; they also likely experience different factors that facilitate or prevent leisure reading compared to children. Moreover, prior work exploring predictors of leisure reading has largely ignored the question of genre. Yet, genre is germane to this topic given that exposure to fiction has demonstrated a stronger association with verbal abilities compared to nonfiction (Mar \& Rain, 2015). Therefore, the purpose of this study was to develop a broad measure of predictors of leisure reading for adults — the Predictors of Leisure Reading (PoLR) scale — encompassing facets of reading motivations, reading obstacles, reading attitudes, and reading interests. We then explored whether these facets of leisure reading predict verbal ability in undergraduates, testing both direct relations as well as indirect effects via exposure to fiction and nonfiction texts.

As children develop from newly minted readers to fully literate young adults, the choice of whether to engage in leisure reading during their free time becomes increasingly autonomous and less related to environmental factors. Yet, little is known about the predictors of leisure reading in adults because the focus of prior research has been mostly on children. A review of 92 articles from 2003 to 2013 found that only 7\% focused on college students and adults (Conradi et al., 2013). Similarly, a review of 16 reading motivation scales found only one intended for adults 
(Davis et al., 2018). This is perplexing because leisure reading in adults remains strongly associated with language and literary skills (Mol \& Bus, 2011). Here, we extend the literature on this topic by studying individuals in young adulthood, a period that ranges in age from the late teens to the start of one's thirties. We developed the Predictors of Leisure Reading (PoLR) scale to better understand leisure reading and its association with verbal ability in young adults. In doing so, we included a broad range of factors that promote, deter, and characterize leisure reading. This culminated in a focus on four possible predictors of leisure reading: reading motivations, reading obstacles, reading attitudes, and reading interests.

\section{Reading Motivations}

People who are intrinsically motivated to participate in activities do so because they find them inherently enjoyable (Conradi et al., 2014; Ryan \& Deci, 2000). In the case of reading, individuals might be driven toward leisure reading because they enjoy being transported to another place or time (Gerrig, 1993), they want to experience the emotions evoked by a book (Mar et al., 2011), and/or they appreciate living vicariously through a fictional character (Jensen et al., 2016). Likewise, readers may seek out texts that allow them to identify with new ways of thinking (Miall \& Kuiken, 2002), to access new information (Gear et al., 2004), or perhaps because they want to grow intellectually or spiritually (Mar et al., 2006). In research with children and adolescents, these types of motivations have typically been viewed as intrinsic in nature, making them likely predictors of leisure reading.

In a study of reading motivation in children, Troyer and colleagues (2019) placed "reading to gain novel perspectives and information" under a broader factor labelled "intrinsic motivation". The authors also included "involvement" (i.e., narrative engagement or transportation), "self-efficacy" (i.e., feeling like a good reader), and "autonomous reading” (i.e., 
enjoying reading) in this factor. These four indices of intrinsic motivation positively predicted both amount of reading and reading comprehension in elementary school students. In contrast, extrinsic motivation (e.g., reading for recognition or grades) negatively predicted amount of reading and reading comprehension in these students. Interestingly, the amount of reading done over the year did not uniquely contribute to reading comprehension beyond intrinsic and extrinsic motivation. Troyer and colleagues (2019) concluded that the match between the reader and book might be more important to reading comprehension than simply the raw quantity of books being read. A similar conclusion can be drawn from the study by Mol and Jolles (2014), who found that having a favorable outlook on reading was positively related to academic achievement in middle schoolers. This relation was even observed in students who described themselves as "non-readers" (i.e., readers who did not read as often as they would have liked). These results suggest that intrinsic motivation, such as having an enjoyment of reading, is associated with positive academic outcomes, and not merely the sheer amount of reading.

The relation between reading motivation and academic performance highlights the importance of promoting reading for enjoyment (Hebbecker et al., 2019). Not surprisingly, interviews with students reveal that they are more motivated to read books that are about topics they enjoy (Brinda, 2011). As part of a multi-tiered intervention, Kim and colleagues (2016) found that using high interest books increased the amount that students read, which in turn, increased their language and reading skills. However, although these researchers examined both fiction and nonfiction, they did not investigate the separate effects of these two genres, which is one of the main aims of the current research.

In one of the few studies with adults, Schutte and Malouff (2007) adapted the children's Motivation for Reading Questionnaire (Wigfield \& Guthrie, 1997) to determine what motivates 
adults to read. One of the key motivating factors to emerge was "reading as part of the self." This factor was related to reading enjoyment and amount (frequency and estimated time spent on leisure reading per week). A second factor to emerge was "reading for recognition." It related more to extrinsic motivation and was not associated with reading enjoyment or amount. Together, these results suggest that intrinsic reading motivations, such as viewing reading as an important part of oneself, are likely to show stronger links to leisure reading than extrinsic motivations. However, more research is needed to clarify whether intrinsic and extrinsic forms of reading motivations predict verbal ability in young adults. It also remains unclear how these relations intersect with genre. It is possible that reading motivations, especially those capturing intrinsic value, might relate differently to fiction and nonfiction.

\section{Reading Obstacles}

Leisure reading is declining at a faster rate among young adults in America (aged 18-24) compared to the rest of the population (The National Endowment for the Arts, 2004). This worrying trend highlights the importance of studying obstacles to leisure reading in young adults. Applegate and Applegate (2004) addressed this issue in a survey of 379 undergraduate students. They found that over half reported receiving little-to-no enjoyment from reading. When asked why, $12 \%$ of the sample indicated that their negative opinions about reading had been shaped in school, by "reading dull books" and "doing book reports," or by being taught by teachers who “did not make reading interesting” (Applegate \& Applegate, 2004, p. 560). These findings, now twice replicated (Applegate et al., 2014; Nathanson et al., 2008), show that feelings of disinterest and displeasure are important obstacles to leisure reading.

The association between negative reading experiences in formal education and a reduced interest in leisure reading has also been reported among children. For example, Becker and 
colleagues (2010) followed over 700 students in Grades 3 to 6 and found that when students read to meet the demands of school (e.g., to maintain good grades), they were less likely to report reading for pleasure. This extrinsic pressure to read was detrimental to literacy skills even when the amount of reading was taken into consideration. Similarly, a study of children in Grades 4 and 5 showed that extrinsic motivation predicts less reading over the summer (Troyer et al., 2019). Thus, in addition to reading motivation, these studies highlight the need to examine the obstacles that may prevent people from engaging in leisure reading.

\section{Reading Attitudes}

Attitudes have been defined as "a set of acquired feelings that consistently predispose an individual to engage in or avoid reading" (Conradi et al., p. 154). Unfortunately, very little research has examined reading attitudes in adults. However, work with children has found that fostering positive experiences with storybooks before school entry can influence how children think and feel about reading (Mol \& Bus, 2011; Sénéchal \& LeFevre, 2002; Weinberger, 1996). As children mature, these attitudes can result in tangible differences in reading behaviors and language abilities over time (Baker et al., 1997; Sénéchal, 2006; Sénéchal \& LeFevre, 2002). For example, participants who had a favorite book at age 3 had more advanced reading abilities at age 7 compared to those who did not (Weinberger, 1996). In kindergarten children, the frequency of shared storybook reading with parents and the number of storybooks in the home directly predicted how much children read for pleasure in Grade 4 (Sénéchal, 2006). Similarly, the number of storybooks remembered from childhood predicted attitudes toward leisure reading held by adolescents in high school (Tremblay et al., 2019). In other words, children who remembered more storybooks from their childhood grew into adolescents who held more positive attitudes towards leisure reading and subsequently read more books. Research by Sikora 
and colleagues. (2018) also highlights the importance of adolescent reading experiences. In a study of over 106,000 adults, the authors found that individuals who reported growing up with larger home libraries at age 16 exhibited better literacy, numeracy, and technological skills during adulthood. Sikora and colleagues posited that early home experiences contributed to a favorable attitude towards literacy practices in general, and that these practices went on to positively influence a plethora of other cognitive abilities. In sum, attitudes about the functions and enjoyment of reading begin early and continue to exert influence on readers as they age (Baker at al., 1997; Sénéchal, 2006; Sénéchal \& LeFevre, 2002). Still, more work is needed to clarify the role of reading attitudes in adulthood.

\section{Reading Interests}

Conradi and colleagues (2013) define individual reading interest as "a relatively stable and enduring positive orientation toward reading about a particular topic" (p. 154). Here, we extend this definition to encompass not only topics, but also interest in specific books and series. For example, readers with high interest might extend their experience in-between reading sessions by continuing to think about the books. These individuals might also be more inclined to read entire series from start to finish, and/or reread their favorite books multiple times. Empirically, these kinds of reading behaviors have been shown to predict language and literacy skills. For example, rereading passages has been found to improve reading fluency in elementary school children (Martin-Chang \& Levy, 2005; Martin-Chang et al., 2007) and support reading comprehension in undergraduates (Margolin \& Snyder, 2018).

To our knowledge, these behaviours have not been documented in the literature examining leisure reading. Nevertheless, it seems intuitive that variability exists between undergraduates who skim texts and easily abandon books compared to those who line up at 
midnight to get the next installment of a beloved series (Cain, 2019). But do such differences in reading interests relate to what sort of texts they are likely to read, such as fiction or nonfiction? And do they continue to affect verbal ability into young adulthood? Due to the paucity of work on these questions, our investigation offers a novel and exploratory examination of reading interests in relation to reading volume and language outcomes.

\section{Fiction versus Nonfiction}

Genre adds another layer of nuance in the relation between leisure reading and verbal abilities, with fiction and nonfiction being the broadest meaningful genre distinction (Graesser et al., 1991). Past work has found that reading fiction has a far stronger association with verbal abilities relative to nonfiction, for both children and young adults (Acheson et al., 2008; Mar \& Rain, 2015; Spear-Swerling et al., 2010). Moreover, after controlling for the shared variance between the two genres, exposure to fiction continues to predict verbal ability, whereas exposure to nonfiction has very weak associations with linguistic skills (McGeown et al., 2015). In fact, nonfiction exposure can even predict worse verbal ability, depending on the type of verbal skill in question (Mar \& Rain, 2015; Spear-Swerling et al., 2010). It has been postulated that different types of motivation drive interactions with these two broad genres of text. Ho and Guthrie (2015) found that many young students scored high in reading ability for nonfiction texts, even though they reported disliking them; the same pattern was seldom the case for fiction, however. Simply put, intrinsic motivation appears to be more important when it comes to reading fiction. When texts are unmotivating, individuals appear more likely to persevere and excel when presented with nonfiction compared to fiction. This is likely because mandatory reading (as opposed to leisure reading) typically focuses on nonfiction texts.

Taken together, past research with children demonstrates that the factors that predict 
leisure reading are varied. The factors may interact with genre and they may differentially relate to language and reading abilities (e.g., Logan et al., 2011). In this study, we examined whether this work generalizes to adults by developing the PoLR scale to investigate how key predictors of leisure reading — reading motivations, obstacles, attitudes, and interests — relate to verbal ability in adults, both directly and indirectly via exposure to fiction and nonfiction texts.

\section{Method}

\section{Participants}

Participants were recruited via an undergraduate participant pool and received course credit for their participation. We collected data from 249 participants across two sessions. Participants who completed only one of the two sessions for this study were excluded from the analysis sample $(n=49)$. The final sample consisted of 200 undergraduate students (males $n=$

62) with a mean age of 20.73 years $(S D=5.67)$. On average, the participants had received 13.86 years of schooling $(S D=1.94)$ and reported being fluent in English for most of their life $(M=$ 20.23, $S D=5.95)$

\section{Materials}

\section{Predictors of Leisure Reading}

To develop a broad and inclusive measure of factors related to leisure reading among adults, we surveyed the literature and uncovered just one measure related to adult reading motivation, the Adult Motivation for Reading Scale (ARMS; Schutte \& Malouff, 2007), which was adapted from the children's Motivation to Read Questionnaire (Wigfield \& Guthrie, 1997). In the ARMS measure, reading obstacles are conceptualized as the inverse of reading motivations, with both existing along the same continuum. In contrast, we conceptualized reading obstacles as a separate construct, as there are likely other obstacles to reading separate 
from low motivation. We further expanded on the ARMS measure by including additional factors relevant for adult leisure reading, namely attitudes toward reading and reading interests.

To develop our measure, we first compiled reading motivation and obstacle items from existing scales, irrespective of target population (i.e., child, adolescent, or adult; e.g., ARMS; Schutte \& Malouff, 2007). This large set of items was then winnowed down by removing identical items, synonymic items, and those items that are unlikely to apply to an adult population (e.g., "I read aloud to myself."). Additional items related to reading motivations and reading obstacles not covered by existing scales were also added. The list of items was systematically reviewed and refined to best capture the diverse motivations and obstacles of adult readers. This process resulted in 17 items measuring reading motivations and 15 items measuring reading obstacles. None of the reading obstacles items were directly inverse of any motivation item. Reading motivation items were written in the form of "I read to/for/because..." statements (Table 2), whereas reading obstacles items adopted the form, "I often don't read because..." (Table 3).

To capture a broad range of possible predictors for reading, we included items designed to measure attitudes toward reading and different interests in reading. To that end, 8 items were generated to capture a wide range of reading attitudes (Table 4), and 8 items to evaluate reading interests (Table 5). Together, these 48 items made up the Predictors of Leisure Reading (PoLR) scale, with four distinct subscales: reading motivations, reading obstacles, reading attitudes, and reading interests (see Tables 2, 3, 4, and 5, respectively).

\section{Leisure Reading of Fiction and Nonfiction Genres}

To measure the extent of adults' leisure reading, we used a reliable estimate of print exposure: the Author Recognition Test-Revised (ART-R; Fong et al., 2013). An ART employs a 
long list of names, with participants asked to select the names they recognize as authors.

Critically, the list contains the names of real authors as well as non-authors (i.e., foils).

Participants are instructed to select only the names they recognize as real authors while being mindful to avoid foils, as these items count against their overall performance. The latter serves to reduce guessing behavior among participants. Performance on the ART correlates strongly with reading experience. Those who recognize more real author names on the ART identify more authors that they themselves have read (Martin-Chang \& Gould, 2008) as well as report greater time spent reading (Acheson et al., 2008). In other words, although respondents may recognize authors that they have not read themselves, overall ART performance reflects print exposure accrued over the lifespan of leisure reading (Stanovich et al., 1996). Accordingly, the ART is a strong predictor of language and literacy skills (Mol \& Bus, 2011).

The author and foil names in the ART have been revised over the years to reflect changes in an author's popularity or the frequency with which their name appears in published works (e.g., Acheson et al., 2008; Martin-Chang \& Gould, 2008). The ART-R used in this study allows for separate measurement of exposure to fiction and nonfiction texts (Fong et al., 2013). It includes 110 fiction author names spanning five genres (Domestic, Foreign, Romance, SciFi/Fantasy, Suspense), 50 nonfiction author names also across five genres (Business, Philosophy/Psychology, Science, Self-Help, Social/Political Commentary), and 40 foil (nonauthor) names. (NB. Two fiction author names were misspelled and thus excluded from all analyses).

\section{Verbal Ability Tasks}

Synonyms. A multiple-choice measure of synonym knowledge presented 60 target words, each with 4 possible options (Mar \& Rain, 2015). For example, participants were 
instructed to "Select the word below whose meaning is closest to: 'cumulative', with four possible options: wholesome, satisfactory, obsolete, and amassing." A past study using these items found that it had good reliability ( $\alpha=.91$; Mar \& Rain, 2015).

Sentence Completion. Sentence completion items were taken from the reading section of the Scholastic Aptitude Test (SAT), a standardized test used as an important entrance criterion for many colleges and universities in the United States. An example item is, “The novel's protagonist, a pearl diver, naïvely expects that the buyers will compete among themselves to pay him the best price for his pearl, but instead they to him." Five possible options were presented. These include incorrect answers, such as "refuse . . cheat" for this example item, and the one correct answer, "collude . . swindle". A total of 28 items were presented, identical to those used in a prior study, which found good reliability for this set of items $(\alpha=.81$; Mar $\&$ Rain, 2015).

Analogies. Analogy items were also drawn from the reading section of the SAT. An example item presents the partial analogy, "Play is to actor as concert is to..." and provides four possible options for completion. These include three incorrect answers (e.g., "Percussion") and the one correct answer (i.e., "Musician). This set of 20 items has previously shown moderate internal reliability $(\alpha=.60 ;$ Mar $\&$ Rain, 2015).

\section{Procedure}

The study was conducted over two 30-minute sessions, scheduled no more than one week apart. Participants completed the study in a laboratory, with all assessments administered via the Qualtrics online survey platform. Participants completed all measures independently, though research assistants were available to answer questions. The PoLR scale, sentence completion task, and analogies task were administered in the first session. The synonyms task was 
administered in the second session (among a battery of other tasks not germane to the purpose of the current study ${ }^{1}$ ). Demographic information was collected in both sessions.

\section{Data Analysis}

The main goal of this study was to investigate how key predictors of leisure reading relate to verbal abilities in adults, examining both direct and indirect links via fiction and nonfiction print exposure. To this end, the four PoLR subscales - reading motivations, obstacles, attitudes, and interests - were evaluated in separate analyses. First, we used exploratory factor analysis (EFA) to test whether the items reflect one or more facet-level latent traits for reading motivations, reading obstacles, reading attitudes, and reading interests. In other words, we explored whether the four subscales would best be broken down into even smaller facets of each subscale. EFAs were performed using maximum-likelihood extraction and oblique goemin rotation (unless otherwise noted). Latent facets (i.e., factors) were retained based on eigenvalues (greater than 1), scree plots, and parallel analysis (Hayton et al., 2004). We examined the factor loadings of each item onto each factor to discern the meaning of the retained facets.

Next, to test whether predictors of leisure reading relate to verbal abilities, we used exploratory structural equation modeling, which integrates the factor optimization of EFA with the rigor of traditional SEM, thus providing a more flexible and ecologically valid approach to fitting complex data (Asparouhov, \& Muthén, 2009; Marsh et al., 2020). The use of exploratory structural equation modeling was critical in retaining the optimal factor structures obtained from EFA — the latent facets of each subscales — enabling us to test the relations between these specific facets of leisure reading and adults' verbal abilities, both directly and indirectly via print exposure. 
Exploratory structural equation modeling used target rotation, which balances the flexible factor loading approach of EFA with the a priori approach of confirmatory factor analysis (Browne, 2001; Marsh et al., 2020). Full information maximum likelihood robust estimation was used to guard against bias due to potential non-normality and non-independence of observations (Finney \& DiStefano, 2013), and to handle missing data (Enders, 2012). A variety of goodnessof-fit indices were used to evaluate model fit (Kline, 2016): the comparative fit index (CFI), Tucker-Lewis index (TLI), root mean square error of approximation (RMSEA), and standardized root mean square residual (SRMR). Good model fit can be inferred from a statistically nonsignificant chi-square, CFI and TLI values greater than or equal to .95, and RMSEA and SRMR estimates less than .06 (Kline, 2016). Bias-corrected bootstrapped 95\% confidence intervals were used to evaluate direct and indirect effects (Preacher \& Hayes, 2008).

\section{Results}

Descriptive statistics are presented in Table 1. Inspection of the data for univariate and multivariate outliers, skewness, and other related issues (as per Field, 2009) showed no other indication of data non-normality or other concerns.

\section{Exploratory Factor Analysis}

Exploratory Factor Analysis (EFA) was used to test whether the items of each subscale of the PoLR reflect one or more facet-level latent traits. The final EFA factor loading solutions for each subscale are shown in Tables 2-5.

\section{Reading Motivations}

The reading motivations subscale initially consisted of 17 items. Preliminary inspection of the data showed two items with intercorrelation below .30 (Field, 2009). Items 16 and 17 had mean absolute correlations with other items of .12 and .11, respectively, and were removed from 
subsequent analyses. EFA was performed on the remaining 15 motivation items. Parallel analysis and three eigenvalues above 1.00 supported the decision to retain three factors (Table 2). Each of these factors reflect a different facet of reading motivations. Based on the individual items loading most strongly onto each factor (i.e., factor loadings in boldface in Table 2), Facet 1 appears to represent the motivation of "Reading for Enjoyment," Facet 2 represents the motivation of "Reading to Grow," and Facet 3 represents the motivation of "Reading Due to the Judgement or Attention of Others".

\section{Reading Obstacles}

An EFA was performed on the 15 reading obstacles items. Parallel analysis and three eigenvalues above 1.00 supported the decision to retain three factors. Initial inspection showed that the three factors were not strongly intercorrelated and thus a follow-up EFA with orthogonal varimax rotation was performed to best fit the data. Next, item 15 was removed for having factor loadings below .40. Based on the items loading most strongly onto each of the three retained factors (i.e., factor loadings in boldface in Table 3), Facet 1 represents the obstacle "Circumstances Prevent Otherwise Enjoyable Reading," Facet 2 the obstacle "Do not Enjoy Reading," and Facet 3 the obstacle "Reading is not Socially Valued".

\section{Reading Attitudes}

Of the 8 items in the reading attitudes subscale, 2 items were eliminated due to correlations less than .30 across items (Item $7 M_{|r s|}=.10$; Item $8 M_{|r s|}=.14$ ). EFA was performed on the remaining 6 items. Parallel analysis suggested only one factor should be retained. The items suggest that this facet of reading attitudes represents "self-concept" (Table 4) as they entail reading as critical to one's identity (for a review see Conradi, 2016).

\section{Reading Interests}


EFA was performed on the 8 reading interests items. Parallel analysis and two eigenvalues above 1.00 suggested that two factors be retained. Initial inspection of these factors showed that they were not strongly intercorrelated and thus a follow-up EFA with orthogonal varimax rotation was performed. Item 8 was removed for having factor loadings below .40 . Based on the items loading most strongly onto each of the two factors, Facet 1 represents a reading style of "Surface Interests" behavior, whereas Facet 2 reflects a style of "Engrained Interests" (Table 5).

\section{Correlation Analysis}

Table 6 provides the correlations between all measures. Correlations were also calculated to examine the relations between these measures and the 9 retained facets of the PoLR (across the 4 subscales). To do so, the 9 latent facets were specified using exploratory structural equation modeling with target rotation to formalize the factor structures identified through EFA. For instance, Reading Motivations Facet 1 (Reading for Enjoyment) is specified by freely estimating the factor loading of items 1-5 (loadings in bold), whereas the factor cross-loadings (items 6-15) are targeted to be near zero.

As expected, the measures of verbal ability were strongly intercorrelated (all $r s>.60$ ). Several of the PoLR facets were associated with verbal ability. Reading for Enjoyment (Motivations), Reading Self-Concept (Attitudes) and Engrained Interests (Interests) were all positively associated with all three verbal ability measures. In contrast, the facets Do Not Enjoy Reading (Obstacle) and Reading is not Socially Valued (Obstacle) were negatively associated with all three verbal ability measures. These associations are consistent with prior research and provide an important validation of the PoLR.

\section{Exploratory Structural Equation Modeling Path Analyses}


A series of path analyses were then conducted to examine the unique associations between the PoLR facets and verbal ability. Each of the PoLR subscales was evaluated in a separate path analysis. For each path analysis, we tested the direct contribution of the facets to verbal ability, as well as indirect contributions via fiction and nonfiction print exposure (i.e., mediation). Verbal ability was included as a latent variable derived from the three verbal ability tasks: sentence completion, synonyms, and analogies (factor loadings .87, 91, and 69, respectively). All models controlled for age, gender, and the number of foils checked on the ART (ART Foils). In some cases, inspection of the modification indices was warranted to improve model fit by freeing some of the error covariance between items. These changes were reasonable because some of the error covariance may be attributable to the shared methodology across items (e.g., similar wording of items; Asparouhov \& Muthén, 2009). Fit indices for the four subscale models are shown in Table 7. Each model provided a good fit to the data.

\section{Reading Motivations}

The path analysis for reading motivations appears in Figure 1. Both direct and indirect relations were observed between the three facets and verbal ability. Reading to Grow had a direct negative association with verbal ability $(\beta=-.31 ; 95 \% \mathrm{CI}:-2.08,-0.77)$ and no indirect associations through fiction or nonfiction print exposure. In contrast, Reading for Enjoyment had a large direct positive association with verbal ability $(\beta=.61,95 \% \mathrm{CI}: 1.65,3.27)$ as well as an indirect effect via exposure to fiction $(\beta=.06,95 \% \mathrm{CI}: 0.08,0.62)$. This suggests that individuals motivated to read because they find the experience enjoyable exhibit better verbal ability, and that this can be partially explained by greater exposure to fiction. Although the contrast in results between these two facets may initially seem confusing, these path analyses identify unique associations controlling for shared variance between facets. It thus appears that it 
is actually the Reading for Enjoyment factor that captures most of the relevant variance when it comes to predicting verbal ability and print exposure, consistent with past work on children. What remains in the Reading to Grow factor after taking into account Reading for Enjoyment, the residual variance, is difficult to interpret. This is especially true since the zero-order correlations also show a very weak positive association between Reading to Grow and the verbal ability measures. In other words, the shared variance between Reading for Enjoyment and Reading to Grow is what drives any association between the latter and verbal ability. In addition, Reading to Grow has stronger associations with exposure to nonfiction $(\beta=.12,95 \% \mathrm{CI}$ : -0.16 , 0.87 ) compared to fiction $(\beta=.02,95 \%$ CI: $-1.14,1.17$ ), whereas Reading for Enjoyment has stronger association with fiction $(\beta=.18,95 \% \mathrm{CI}: 0.45,2.58)$ relative to nonfiction $(\beta=.02$, 95\% CI: $-0.48,0.66)$. This is important as it is exposure to fiction that has the stronger association with verbal ability. Thus, people reporting greater motivation to read as a growth experience appear to be focusing on nonfiction in order to learn factual information, which might explain these weaker associations with verbal ability. The final factor, Reading Due to the Judgement or Attention of Others, was associated with greater fiction $(\beta=.07,95 \%$ CI: -0.72 , 1.87) than nonfiction print exposure, but this factor did not contribute to verbal ability (directly or indirectly).

\section{Reading Obstacles}

The path analysis model for reading obstacles is shown in Figure 2. For this model, we correlated the residuals of items 10 and 11 for improved model fit. This was justified as items 10 and 11 have considerable overlap in their wording ("I often don't read because [...] high school ruined it for me [Item 12] / high school made reading less pleasurable" [Item 13]). Both direct and indirect effects were observed between the facets of the reading obstacle subscale and verbal 
ability. The first facet, Circumstances Prevent Otherwise Enjoyable Reading, had unique positive associations with verbal skills. Namely, the results showed a large direct effect $(\beta=.32,95 \%$ CI: $1.42,2.83)$ as well as an indirect effect via fiction exposure $(\beta=.04,95 \%$ CI: $0.05,0.49)$. This factor also had a stronger association with fiction $(\beta=.14,95 \% \mathrm{CI}: 0.70,3.07)$ compared to nonfiction $(\beta=.03,95 \% \mathrm{CI}:-0.28,0.64)$. In contrast, the second facet, Do Not Enjoy Reading, had a large and direct negative association with verbal ability $(\beta=-.56 ; 95 \% \mathrm{CI}:-3.84,-2.40)$, as well as an indirect effect via less fiction exposure $(\beta=-.07 ; 95 \% \mathrm{CI}:-0.70,-0.08)$. This demonstrates that a failure to find pleasure in reading is associated with reduced verbal ability, both directly and as a function of identifying fewer fiction authors. Do not Enjoy Reading had a stronger negative association with fiction $(\beta=-.27,95 \% \mathrm{CI}:-3.97,-1.72)$ relative to nonfiction $(\beta=-.05,95 \% \mathrm{CI}:-0.76,0.22)$. These divergent associations with verbal ability between facets 1 and 2 of reading obstacles highlight the importance of understanding exactly why it is that people do not read. If the reason is intrinsic, we observe negative associations with verbal ability. However, if the issue is extrinsic to the individual, the exact opposite is observed. Moreover, how intrinsic and extrinsic motivation relate to fiction and nonfiction exposure also appears important, with stronger links to fiction being associated with better verbal ability. Lastly, with respect to the third factor of the reading obstacles subscale—-Reading is not Socially Valuedwe uncovered no unique associations with either genre of print exposure or verbal ability.

\section{Reading Attitudes}

The path analysis for reading attitudes appears in Figure 3. Based on inspection of the modification indices, the residuals of items 4 and 6 and items 5 and 6 were permitted to covary given their strong thematic overlap (e.g., reading is a good reflection of me [Item 6] / of others [Item 4]). Likewise, the residuals of items 1 and 2 were permitted to covary because they 
overlapped considerably in wording ("I would like to spend more [Item 1] / less [Item 2] time reading"). For this single factor model of reading attitudes, the facet of Reading is Part of my Self-Concept had a direct association with verbal ability $(\beta=.32,95 \%$ CI: $1.56,3.07)$ and an indirect effect via fiction exposure $(\beta=.07,95 \% \mathrm{CI}$ : $0.16,0.86)$. This facet also had a stronger association with fiction $(\beta=.20,95 \% \mathrm{CI}: 1.52,3.98)$ than nonfiction $(\beta=.05,95 \% \mathrm{CI}:-0.23$, 0.90). This means that individuals who believe reading is important and self-identify as readers tend to have better verbal abilities, partially explained by greater exposure to fictional texts.

\section{Reading Interests}

The path analysis model for reading interests is shown in Figure 4. For this model, the residuals of items 1 and 2 were allowed to covary given the considerable overlap in their wording ("I often skim things I read [...] to get the gist of them"). For the two different facets, only Engrained Interests had unique associations with verbal ability. Specifically, Facet 2 had a direct association with verbal ability $(\beta=.37,95 \% \mathrm{CI}: 0.86,2.37)$ and an indirect effect via fiction exposure $(\beta=.05,95 \% \mathrm{CI}: 0.08,0.59)$. It appears that those who feel most compelled to read and reread familiar series also tend to have better verbal abilities. This preference for reading is mostly associated with fictional genres. Lastly, and perhaps to be expected, the first facet, Surface Interests, showed no direct or indirect associations with verbal ability and rather weak associations with fiction and nonfiction print exposure.

\section{Discussion}

In this investigation, we characterized the complex elements that motivate leisure reading in young adults and evaluated how each element relates to verbal ability, directly or indirectly via exposure to texts. This a timely area of study, as a recent systematic review highlighted the need for more inquiry into the multidimensionality of reading motivation, especially within the 
adult population (Davis et al., 2018). Young adults represent a unique population with respect to reading motivation because they are transitioning into a realm of independence, where the decision to read becomes increasingly autonomous. Delineating the differences associated with reading fiction and nonfiction is also timely, as there is evidence to show that leisure reading of nonfiction has increased by $24 \%$ since 2014 (Flood, 2019). But past research indicates that it is the reading of fiction that is closely associated important benefits like improved verbal ability, rather than nonfiction (Mar \& Rain, 2015).

In order to facilitate future research on this topic with adults, we developed a broad and inclusive measure of the predictors of leisure reading. The PoLR includes four subscales, each representing a broad category related to leisure reading, and each subscale is further broken down into individual facets to provide greater nuance in measurement. These subscales and their facets (see Tables 2-5) were found to predict verbal ability (measured robustly, using 3 tasks) both directly and indirectly via exposure to print, thus forming an important validation of this new scale. Just as importantly, the patterns of associations we uncovered paint a consistent picture across the different predictors: greater intrinsic reading enjoyment is related to more advanced verbal abilities, especially via exposure to fiction texts (Ho \& Guthrie, 2013; Troyer et al., 2019). Indeed, all three measures of verbal ability had stronger associations with reading fiction relative to nonfiction, both in the raw correlations and in the unique associations determined via our path analyses. In addition, it was the predictors that had to do with truly enjoying reading and identifying as a reader that uniquely predicted better verbal abilities.

In contrast, participants who related to the items associated with extrinsic pressures typically had weaker verbal abilities and stronger links to nonfiction exposure (either more positive, or less negative). This was exemplified by one facet of reading obstacles: 
Circumstances Prevent Enjoyable Reading. Despite higher scores on this facet indicating a lack of concurrent reading behaviour, the attestation that reading is still an enjoyable activity remained a unique direct predictor of verbal abilities (with some evidence of indirect association via fiction exposure). As a whole, this pattern of associations is largely consistent with prior work examining reading motivation among children (Mol \& Jolles, 2014), which highlights the continuity of influences across different stages of education.

Our data stress the value of reading for enjoyment: to relax, to be entertained, to become immersed in other worlds, and to experience emotions of other characters. Teachers at all levels should encourage students to read books they enjoy, give students the option of continuing within a series they are attached to, and give students the choice of rereading books they love. Implementing these suggestions, along with modeling a love for reading (McKool \& Gespass, 2009) and teaching explicit reading strategies (Kim et al., 2016), may be the clearest path to ensuring that leisure reading becomes a life-long habit. Sadly, 35\% of our participants selected the statement "I do not enjoy reading because being asked to analyze books in high school made it less pleasurable". If teachers wish to prevent students from "learning to hate reading" in school (Brinda, 2011, p. 9), they should avoid making reading a chore.

\section{Limitations}

In developing the PoLR scale, our study revealed important associations between specific facets of leisure reading and verbal abilities in young adults. In doing so, our findings extend past work on this topic, especially with regards to Reading Interests. Still, our final sample size was only 200 adults, and a larger sample would have afforded us greater precision in our estimates. In addition, our measure of print exposure was geared toward a more refined measurement of fiction and its various subgenres and thus included more names for the fiction genre than the 
nonfiction genre. As a result, our measurement of exposure to fiction may have been more reliable and more precise relative to our measure of exposure to nonfiction. That said, our results are consistent with past studies that employed a diversity of different measurement approaches (Acheson et al., 2008; Mar \& Rain, 2015; Spear-Swerling et al., 2010).

\section{Future Directions}

The findings reported here underline the many questions in this area that remained to be answered. For example, the direct associations we observed between Reading for Enjoyment and verbal ability demonstrate that print exposure alone does not completely mediate the relationship between having a favorable outlook towards reading and being skilled at using language. At least, not as measured by our ART, which undoubtedly contains some measurement error. Future work can help elucidate these direct and indirect associations. To speculate, it may be that more expansive measures of print exposure are required, in addition to other types of self-report measures for reading behavior, in order to reduce measurement error. Alternatively, it may be that individuals who enjoy reading approach and/or absorb text in ways that are qualitatively different than those who are less enthusiastic about reading. Our creation of the PoLR will help to facilitate future investigations in this area.

\section{Conclusion}

There is no longer any question that reading is tied to many important outcomes. In addition to its obvious association with verbal abilities, voracious readers exhibit the ability to better understand others (Mar, 2018; Mumper \& Gerrig, 2017) and show reduced prejudice towards stigmatized members of society (Vezzali et al., 2015). Those who read more as children attain a higher socioeconomic status (SES) as adults, even after controlling for SES at birth, education, intelligence, and academic motivation (Ritchie \& Bates, 2013). If any further 
evidence is needed, enthusiastic readers live longer healthier lives relative to those who read less (e.g., Bavishi et al., 2016). In sum, there are a great many avenues to explore when it comes to the important outcomes of reading, and the PoLR will help future researchers tease apart the factors that influence whether or not undergraduates choose to spend their free time in the company of good books. 


\section{References}

Acheson, D. J., Wells, J. B., \& MacDonald, M. C. (2008). New and updated tests of print exposure and reading abilities in college students. Behavior Research Methods, 40, 278289. https://doi.org/10.3758/BRM.40.1.278

Applegate, A. J., \& Applegate, M. D. (2004). The Peter Effect: Reading habits and attitudes of preservice teachers. The Reading Teacher, 57, 554-563. Retrieved from https://www.jstor.org/stable/20205399

Applegate, A. J., Applegate, M. D., Mercantini, M. A., McGeehan, C. M., Cobb, J. B., DeBoy, J. R., ... Lewinski, K. E. (2014). The Peter Effect revisited: Reading habits and attitudes of college students. Literacy Research and Instruction, 53, 188-204. https://doi.org/10.1080/19388071.2014.898719

Asparouhov, T., \& Muthén, B. (2009). Exploratory structural equation modeling. Structural Equation Modeling, 16, 397-438. https://doi.org/10.1080/10705510903008204

Baker, L., Scher, D., \& Mackler, K. (1997). Home and family influences on motivations for reading. Educational Psychologist, 32, 69-82. https://doi.org/10.1207/s15326985ep3203_2

Bavishi, A., Slade, M., \& Levy, B. (2016). A chapter a day: Association of book reading with longevity. Social Science \& Medicine, 164, 44-48. https://doi.org/10.1016/j.socscimed.2016.07.014

Becker, M., McElvany, N., \& Kortenbruck, M. (2010). Intrinsic and extrinsic reading motivation as predictors of reading literacy: A longitudinal study. Journal of Educational Psychology, 102, 773-785. https://doi.org/10.1037/a0020084

Brinda, W. (2011). A “ladder to literacy” engages reluctant readers. Middle School Journal, 43, 8-17. https://doi.org/10.1080/00940771.2011/11461796 
Browne, M. W. (2001). An overview of analytic rotation in exploratory factor analysis.

Multivariate Behavioral Research, 36, 111-150. https://doi.org/10.1207/S15327906MBR $\underline{3601 \_05}$

Cain, S. (Sept 10, 2019). 'She's a prophet': handmaids gather for Margaret Atwood's midnight launch of The Testaments. The Guardian, https://www.theguardian.com/books/2019/sep/10/shes-a-prophet-handmaids-gather-formargaret-atwoods-midnight-launch-of-the-testaments

Conradi, K., Jang, B.G., McKenna, M. (2014). Motivational terminology in reading research: A conceptual review. Educational Psychology Review, 26, 127-164. https://doi.org/10.1007/s10648-013-9245-Z

Cunningham, A. E., Perry, K. E., \& Stanovich, K. E. (2001). Converging evidence for the concept of orthographic processing. Reading and Writing: An Interdisciplinary Journal, 14, 549-568. https://doi.org/10.1023/A:1011100226798

Davis, M., Tonks, S., Hock, M., Wang, W., Rodriguez, A. (2018). A review of reading motivation scales. Reading Psychology, 39, 121-187. https://doi.org/10.1080/02702711.2017.1400482

Enders, C. K. (2013). Dealing with missing data in developmental research. Child Development Perspectives, 7, 27-31. https://doi.org/10.1111/cdep.12008

Field, A. (2009). Discovering statistics using SPSS. SAGE.

Finney, S. J., \& DiStefano, C. (2013). Nonnormal and categorical data in structural equation modeling. In G. R. Hancock \& R. O. Mueller (Eds.), Structural equation modeling: A second course (2nd ed., pp. 439-492). Information Age. 
Flood, A. (June 28, 2019). Death of the novel is greatly exaggerated, say UK booksellers. The Guardian. https://www.theguardian.com/books/2019/jun/28/death-of-the-novel-isgreatly-exaggerated-say-uk-booksellers

Fong, K., Mullin, J. B., \& Mar, R. A. (2013). What you read matters: The role of fiction genres in predicting interpersonal sensitivity. Psychology of Aesthetics, Creativity, and the Arts, 7, 370-376. https://doi.org/10.1037/a0034084

Gear, A., Wizniak, R., \& Cameron, J. (2004). Rewards for reading a review of seven programs. Alberta Journal of Educational Research, 50, 200-203.

Gerrig, R. J. (1993). Experiencing narrative worlds. Yale University Press.

Graesser, A., Golding, J. M., \& Long, D. L. (1991). Narrative representation and comprehension. In R. Barr, M. L. Kamil, P. B. Mosenthal, \& P. D. Pearson (Eds.), Handbook of reading research (Vol. 2, pp. 171-205). Lawrence Erlbaum.

Hayton, J. C., Allen, D. G., \& Scarpello, V. (2004). Factor retention decisions in exploratory factor analysis: A tutorial on parallel analysis. Organizational Research Methods, 7(2), 191-205. https://doi.org/10.1177/1094428104263675

Hebbecker, K., Förster, N., \& Souvignier, E. (2019). Reciprocal effects between reading achievement and intrinsic and extrinsic motivation. Scientific Studies of Reading, 23, 419-436. https://doi.org/10.1080/10888438.2019.1598413

Ho, A. N., \& Guthrie, J. T. (2013). Patterns of association among multiple motivations and aspects of achievement in reading. Reading Psychology, 34, 101-147. https://doi.org/10.1080/02702711.2011.596255

Jensen, J. D., Christy, K., Krakow, M., John, K., \& Martins, N. (2016). Narrative transportability, leisure reading, and genre preference in children 9-13 years old. The 
Journal of Educational Research, 109, 666-674.

https://doi.org/10.1080/00220671.2015.1034351

Kavanagh, L. (2019). Relations between children's reading motivation, activity and performance at the end of primary school. Journal of Research in Reading, 42, 562-582. https://doi.org/10.1111/1467-9817.12284

Kim, J. S., Hemphill, L., Troyer, M., Thomson, J. M., Jones, S. M., LaRusso, M. D., \& Donovan, S. (2016). Engaging struggling adolescent readers to improve reading skills. Reading Research Quarterly, 52, 357-384. https://doi.org/10.1002/rrq.171

Kline, R. B. (2016). Principles and practice of structural equation modeling (4th ed.). Guilford.

Logan, S., Medford, E., \& Hughes, N. (2011). The importance of intrinsic motivation for high and low ability readers' reading comprehension performance. Learning and Individual Differences, 21, 124-128. https://doi.org/10.1016/j.lindif.2010.09.011

Mar, R. A. (2018). Evaluating whether stories can promote social cognition: introducing the social processes and content entrained by narrative (SPaCEN) framework. Discourse Processes, 55, 454-479. https://doi.org/10.1080/0163853X.2018.1448209

Mar, R. A., \& Rain, M. (2015). Narrative fiction and expository nonfiction differentially predict verbal ability. Scientific Studies of Reading, 19, 419-433. https://doi.org/10.1080/10888438.2015.1069296

Mar, R. A., Oatley, K., Djikic, M., \& Mullin, J. (2011). Emotion and narrative fiction: Interactive influences before, during, and after reading. Cognition and Emotion, 25, 818-833. https://doi.org/10.1080/02699931.2010.515151

Mar, R. A., Oatley, K., Hirsh, J., dela Paz, J., \& Peterson, J. B. (2006). Bookworms versus nerds: Exposure to fiction versus non-fiction, divergent associations with social ability, and the 
simulation of fictional social worlds. Journal of Research in Personality, 40, 694-712. https://doi.org/10.1016/j.jrp.2005.08.002

Margolin. S., \& Snyder, N. (2018). It may not be that difficult the second time around: the effects of rereading on the comprehension and metacomprehension of negated text. Journal of Research in Reading, 41(2), 392- 402. https://doi.org/10.1111/1467-9817.12114

Marsh, H. W., Guo, J., Dicke, T., Parker, P. D., \& Craven, R. G. (2020). Confirmatory factor analysis (CFA), exploratory structural equation modeling (ESEM), and set-ESEM: Optimal balance between goodness of fit and parsimony. Multivariate Behavioral Research, 55, 102-119. https://doi.org/10.1080/00273171.2019.1602503

Martin-Chang, S., \& Gould, O. N. (2008). Revisiting print exposure: Exploring differential links to vocabulary, comprehension, and reading rate. Journal of Research in Reading, 31, 273-284. https://doi.org/10.1111/j.1467-9817.2008.00371.x

Martin-Chang, S., \& Levy, B. A. (2005). Fluency transfer: Differential gains in reading speed and accuracy following isolated word and context training. Reading and Writing, 18(4), 343-376. https://doi.org/10.1007/s11145-005-0668-X

Martin-Chang, S., Levy, B. A., \& O’Neil, S. (2007). Word acquisition, retention, and transfer: Findings from contextual and isolated word training. Journal of Experimental Child Psychology, 96, 37-56. https://doi.org/10.1016/j.jecp.2006.08.004

McGeown, S. P., Duncan, L. G., Griffiths, Y. M., \& Stothard, S. E. (2015). Exploring the relationship between adolescent's reading skills, reading motivation and reading habits. Reading and Writing: An Interdisciplinary Journal, 28, 545-569. https://doi.org/10.1007/s11145-014-9537-9 
McKool, S.S., \& Gespass, S. (2009). Does Johnny's reading teacher love to read? How teachers' personal reading habits affect instructional practices. Literacy Research and Instruction, 48, 264-276. http://doi.org/10.1080/19388070802443700

Miall, D. S., \& Kuiken, D. (2002). A feeling for fiction: Becoming what we behold. Poetics, 30, 221-241. https://doi.org/10.1016/S0304-422X(02)00011-6

Mol, S. E., \& Bus, A. G. (2011). To read or not to read: A meta-analysis of print exposure from infancy to early adulthood. Psychological Bulletin, 137, 267-296. https://doi.org/10.1037/a0021890

Mol, S. E., \& Jolles, J. (2014). Reading enjoyment amongst non-leisure readers can affect achievement in secondary school. Frontiers in Psychology, 27, 1-10. https://doi.org/10.3389/fpsyg.2014.01214

Mumper, M. L., \& Gerrig, R. J. (2017). Leisure reading and social cognition: A meta-analysis. Psychology of Aesthetics, Creativity, and the Arts, 11, 109-120. http://dx.doi.org/10.1037/aca000089

Nathanson, S., Pruslow, J., \& Levitt, R. (2008). The reading habits and literacy attitudes of inservice and prospective teachers: Results of a questionnaire survey. Journal of Teacher Education, 59, 313-321. https://doi.org/10.1177/0022487108321685

National Endowment for the Arts (2007). To read or not to read: A question of national consequence. Retrieved October 27, 2019 from https://www.arts.gov/sites/default/files/ToRead.pdf

Ritchie, S. J., \& Bates, T. C. (2013). Enduring links from childhood mathematics and reading achievement to adult socioeconomic status. Psychological Science, 24, 1301-1308. https://doi.org/10.1177/0956797612466268 
Ryan, R. M., \& Deci, E. L. (2000). Self-determination theory and the facilitation of intrinsic motivation, social development, and well-being. American Psychologist, 55, 68-78. https://doi.org/10.1037/0003-066X.55.1.68

Schutte, N., \& Malouff, J. (2007). Dimensions of reading motivation: Development of an adult reading motivation scale. Reading Psychology, 28, 469-489. https://doi.org/10.1080/02702710701568991

Sénéchal, M. (2006). Testing the home literacy model: Parental involvement in kindergarten is differentially related to grade 4 reading comprehension, fluency, spelling, and reading for pleasure. Scientific Studies of Reading, 10, 59-87. https://doi.org/10.1207/s1532799xssr1001_4

Sénéchal, M., \& LeFevre, J. (2002). Parental involvement in the development of children's reading skill: A five-year longitudinal study. Child Development, 73, 445-460. https://doi.org/10.1111-1467-8624.00417

Sikora, J., Evans, M. D. R., \& Kelley, J. (2019). Scholarly culture: How books in adolescence enhance adult literacy, numeracy and technology skills in 31 societies. Social Science Research, 77, 1-15. https://doi.org/10.1016/j.ssresearch.2018.10.003

Spear-Swerling, L., Brucker, P. O., \& Alfano, P. O. (2010). Relationships between sixth-graders' reading comprehension and two different measures of print exposure. Reading and Writing: An Interdisciplinary Journal, 23, 73-96. https://doi.org/10.1007/s11145-008$\underline{9152-8}$

Stanovich, K. E., West, R. F., Cunningham, A. E., \& Cipielewski, J., \& Siddiqui, S. (1996). The role of inadequate print exposure as a determinant of reading comprehension problems. In 
C. Cornoldi \& J. Oakhill (Eds.), Reading comprehension difficulties. Processes and intervention. (pp. 15-82). Erlbaum.

Stutz, F., Schaffner, E., \& Schiefele, U. (2016). Relations among reading motivation, reading amount, and reading comprehension in the early elementary grades. Learning and Individual Differences, 45, 101-113. https://doi.org/10.1016/j.lindif.2015.11.022

Tremblay, B., Martin-Chang, S., \& Ouellette, G. (2019, July). Do bedtime stories build the foundation for later reading preferences, spelling skills, and vocabulary? Spoken paper presented at the Society for the Scientific Studies of Reading Conference, Toronto, ON, Canada.

Troyer, M., Kim, J. S., Hale, E., Wantchekon, K., \& Armstrong, C. (2019). Relations among intrinsic and extrinsic motivation, reading amount, and comprehension: A conceptual replication. Reading and Writing: An Interdisciplinary Journal, 32, 1197-1218. https://doi.org/10.1007/s11145-018-9907-9

Vezzali, L., Stathi, S., Giovannini, D., Capozza, D., \& Trifiletti, E. (2015). The greatest magic of Harry Potter: Reducing prejudice. Journal of Applied Social Psychology, 45, 105-121. https://doi.org/10.1111/jasp.12279

Weinberger, J. (1996). A longitudinal study of children's early literacy experiences at home and later literacy development at home and school. Journal of Research in Reading, 19, 1424. https://doi.org/10.1111/j.1467-9817.1996.tb00083.x

Wigfield, A., \& Guthrie, J. T. (1997). Relations of children's motivation for reading to the amount and breadth of their reading. Journal of Educational Psychology, 89, 420-432. https://doi.org/10.1037/0022-0663.89.3.420 


\section{Footnotes}

${ }^{1}$ These include measures of need for cognition, empathy, need to belong, personality traits, need for affect, and devices used for reading. Detail and data are available upon request. 


\section{Acknowledgements}

This research was funded by a grant to RM from the Social Sciences and Humanities Research Council (\#435-2012-1420). We thank Colin Decker (University of Toronto) for his assistance with some of the statistical analyses. 
Table 1

Descriptive statistics

\begin{tabular}{|c|c|c|c|}
\hline Measures & Mean $(S D)$ & Min-Max & $\begin{array}{c}\text { Reliability } \\
(95 \% \text { CI })\end{array}$ \\
\hline \multicolumn{4}{|l|}{ Print Exposure } \\
\hline ART Fiction (108) & $8.05(8.02)$ & $0-47$ & - \\
\hline ART Nonfiction (50) & $3.53(3.65)$ & $0-18$ & - \\
\hline ART Foils (40) & $1.01(1.86)$ & $0-12$ & - \\
\hline \multicolumn{4}{|l|}{ Verbal Ability $^{\mathrm{a}}$} \\
\hline Sentence Completion (28) & $14.97(4.90)$ & $3-25$ & $.73(.26, .86)$ \\
\hline Synonyms (60) & $30.20(10.44)$ & $11-56$ & $.82(.74, .85)$ \\
\hline Analogies (20) & $13.16(2.63)$ & $7-19$ & $.94(.91, .94)$ \\
\hline \multicolumn{4}{|l|}{ PoLR ${ }^{\mathrm{b}}$} \\
\hline Reading Motivations & $63.35(14.51)$ & $21-99$ & $.84(.70, .89)$ \\
\hline Facet 1 & $24.23(7.32)$ & $6-35$ & $.88(.85, .91)$ \\
\hline Facet 2 & $31.85(8.16)$ & $7-49$ & $.85(.81, .88)$ \\
\hline Facet 3 & $7.26(3.20)$ & $3-19$ & $.63(.49, .71)$ \\
\hline Reading Obstacles & $40.93(14.92)$ & $14-75$ & $.89(.86, .91)$ \\
\hline Facet 1 & $14.00(4.87)$ & $4-25$ & $.70(.63, .76)$ \\
\hline Facet 2 & $21.60(10.42)$ & $7-49$ & $.91(.88, .93)$ \\
\hline Facet 3 & $5.33(2.39)$ & $3-13$ & $.72(.63, .79)$ \\
\hline Reading Attitudes & $31.31(5.60)$ & $15-42$ & $.73(.63, .79)$ \\
\hline Facet 1 & $31.31(5.60)$ & $15-42$ & $.73(.63, .79)$ \\
\hline Reading Styles & $29.01(6.10)$ & $11-45$ & $.64(.54, .75)$ \\
\hline Facet 1 & $9.24(3.25)$ & $3-18$ & $.62(.48, .70)$ \\
\hline Facet 2 & $19.78(4.37)$ & $6-28$ & $.60(.47, .69)$ \\
\hline
\end{tabular}

Note. $N=200 . S D=$ Standard deviation. ${ }^{\mathrm{a}}$ Categorical omega reliability. ${ }^{\mathrm{b}}$ Hierarchical omega reliability. 
Table 2

Factor Loadings for Reading Motivations Subscale

\begin{tabular}{|c|c|c|c|c|}
\hline Items & $\begin{array}{l}\text { Facet } 1 \\
\text { Reading for } \\
\text { Enjoyment }\end{array}$ & $\begin{array}{l}\text { Facet } 2 \\
\text { Reading to } \\
\text { Grow }\end{array}$ & $\begin{array}{c}\text { Facet } 3 \\
\text { Reading Due to } \\
\text { the Judgement or } \\
\text { Attention of Others }\end{array}$ & $\mathrm{R}^{2}$ \\
\hline 1. I read for entertainment & $.89 *$ & $-.25^{*}$ & -.002 & $66 \%$ \\
\hline 2. I read for pleasure & $.88 *$ & -.11 & -.01 & $70 \%$ \\
\hline 3. I read to relax & $.88 *$ & .01 & -.09 & $78 \%$ \\
\hline $\begin{array}{l}\text { 4. I read to become immersed in the } \\
\text { world of text }\end{array}$ & $.70 *$ & .08 & .04 & $55 \%$ \\
\hline 5. I read to experience certain emotions & $.59 *$ & $.18^{*}$ & .09 & $49 \%$ \\
\hline 6. I read to learn new things & -.02 & $.72 *$ & $-.21 *$ & $47 \%$ \\
\hline $\begin{array}{l}\text { 7. I read to help me better understand } \\
\text { myself }\end{array}$ & .14 & $.70 *$ & -.06 & $57 \%$ \\
\hline 8. I read to better understand others & .17 & $.63^{*}$ & .07 & $56 \%$ \\
\hline 9. I read to improve my language ability & .16 & $.61^{*}$ & .03 & $49 \%$ \\
\hline $\begin{array}{l}\text { 10. I read to be a better role model for } \\
\text { others }\end{array}$ & -.03 & $.56^{*}$ & .17 & $38 \%$ \\
\hline $\begin{array}{l}\text { 11. I read to think in new ways (e.g., be } \\
\text { more creative, expand my world } \\
\text { view) }\end{array}$ & $.32 *$ & $.55^{*}$ & -.04 & $55 \%$ \\
\hline $\begin{array}{l}\text { 12. I read to feel connected to other } \\
\text { people }\end{array}$ & .05 & $.49 *$ & .21 & $36 \%$ \\
\hline $\begin{array}{l}\text { 13. I read because I would feel } \\
\text { guilty/embarrassed if I did not }\end{array}$ & -.07 & -.01 & $.78 *$ & $61 \%$ \\
\hline 14. I read to impress others & -.002 & .05 & $.61 *$ & $38 \%$ \\
\hline 15. I read to avoid interacting with others & $.34^{*}$ & .001 & $.42 *$ & $29 \%$ \\
\hline $\begin{array}{l}\text { 16. I read because of school/work } \\
\text { requirements }^{\mathrm{a}} \\
\text { 17. I read to keep with current culture } \\
\text { (e.g., music, celebrities, current }^{\text {events, news) }} \text { a }^{\mathrm{a}}\end{array}$ & & & & \\
\hline
\end{tabular}

Note. *loading significant at $p<.05$ level. ${ }^{\text {a }}$ Item excluded from final EFA solution. 
Table 3

Factor Loadings for Reading Obstacles Subscale

\begin{tabular}{|c|c|c|c|c|c|}
\hline Items & & $\begin{array}{c}\text { Facet } 1 \\
\text { Circumstances } \\
\text { Prevent Otherwise } \\
\text { Enjoyable Reading }\end{array}$ & $\begin{array}{c}\text { Facet } 2 \\
\text { Do not Enjoy } \\
\text { Reading } \\
\end{array}$ & $\begin{array}{c}\text { Facet } 3 \\
\text { Reading is not } \\
\text { Socially Valued }\end{array}$ & $\mathrm{R}^{2}$ \\
\hline 1.1 & $\begin{array}{l}\text { I often don't read because I don't } \\
\text { have enough time }\end{array}$ & $.70 *$ & $.19 *$ & -.002 & $53 \%$ \\
\hline 2.1 & $\begin{array}{l}\text { I often don't read because I am } \\
\text { feeling too tired }\end{array}$ & $.61 *$ & $.41 *$ & .03 & $51 \%$ \\
\hline 3.1 & $\begin{array}{l}\text { I often don't read because of the } \\
\text { cost }\end{array}$ & $.46^{*}$ & .003 & $.29 *$ & $29 \%$ \\
\hline 4. 1 & $\begin{array}{l}\text { I often don't read because I read all } \\
\text { day at work/school and this } \\
\text { prevents me from enjoying reading }\end{array}$ & $.41 *$ & $.25^{*}$ & $.20^{*}$ & $27 \%$ \\
\hline 5. & $\begin{array}{l}\text { I often don't read because I find it } \\
\text { boring }\end{array}$ & .07 & $.83 *$ & $.21^{*}$ & $74 \%$ \\
\hline 6. & $\begin{array}{l}\text { I often don't read because I never } \\
\text { got in the habit }\end{array}$ & -.002 & $.77 *$ & $.20^{*}$ & $63 \%$ \\
\hline $7 . \quad 1$ & $\begin{array}{l}\text { I often don't read because I don't } \\
\text { have to }\end{array}$ & $.28^{*}$ & $.74 *$ & .05 & $62 \%$ \\
\hline 8.1 & $\begin{array}{l}\text { I often don't read because I don't } \\
\text { see the point }\end{array}$ & .07 & $.73 *$ & $.21 *$ & $58 \%$ \\
\hline 9.1 & $\begin{array}{l}\text { I often don't read because I'd rather } \\
\text { be doing something else }\end{array}$ & $.39 *$ & $.72 *$ & $.13^{*}$ & $69 \%$ \\
\hline 10. & $\begin{array}{l}\text { I often don't read because being } \\
\text { asked to analyze books in high } \\
\text { school made reading less } \\
\text { pleasurable }\end{array}$ & $.35^{*}$ & $.66^{*}$ & $.19 *$ & $59 \%$ \\
\hline 11. & $\begin{array}{l}\text { I often don't read because being } \\
\text { assigned things to read in high } \\
\text { school ruined it for me }\end{array}$ & $.45^{*}$ & $.61 *$ & $.13^{*}$ & $59 \%$ \\
\hline 12. & $\begin{array}{l}\text { I often don't read because my } \\
\text { friends don't like to read }\end{array}$ & .04 & $.27 *$ & $.70 *$ & $57 \%$ \\
\hline 13. 1 & $\begin{array}{l}\text { I often don't read because reading } \\
\text { is not seen as cool }\end{array}$ & -.03 & $.38 *$ & $.68^{*}$ & $60 \%$ \\
\hline 14. & $\begin{array}{l}\text { I often don't read because materials } \\
\text { are not accessible to me where I } \\
\text { live }\end{array}$ & $.31 *$ & .07 & $.57 *$ & $42 \%$ \\
\hline 15. & $\begin{array}{l}\text { I often don't because I find it } \\
\text { difficult }^{\mathrm{a}}\end{array}$ & & & & \\
\hline
\end{tabular}


Table 4

Factor Loadings for Reading Attitudes Subscale

\section{Facet 1}

Reading is part of my

1. I would like to spend more time reading $.77 *$ $60 \%$

2. I would like to spend less time reading ${ }^{\mathrm{a}}$ $.67 *$ $45 \%$

3. It is important to be well-read $.64 *$ $41 \%$

4. You can tell a lot about a person by what s/he reads $.54 *$ $29 \%$

5. I think of myself as a reader $.48 *$ $23 \%$

6. I feel that what I read is a good reflection of who I am as a person

$.45 *$ $20 \%$

7. I sometimes feel embarrassed about what I choose to read $^{\mathrm{a}}$

8. I don't understand why some people read certain genres (e.g., sci-fi, romance, history) ${ }^{\mathrm{b}}$

Note. ${ }^{*}$ loading significant at $p<.05$ level. ${ }^{\text {a }}$ Reversed scored for analyses. ${ }^{\mathrm{b}}$ Item excluded from final EFA solution. 
Table 5

Factor Loadings for Reading Interests Subscale

\begin{tabular}{|c|c|c|c|}
\hline Items & $\begin{array}{c}\text { Facet } 1 \\
\text { Surface } \\
\text { Interests }\end{array}$ & $\begin{array}{c}\text { Facet } 2 \\
\text { Engrained } \\
\text { Interests } \\
\end{array}$ & $\mathrm{R}^{2}$ \\
\hline $\begin{array}{l}\text { 1. I often skim things I read online to get the } \\
\text { gist of them }\end{array}$ & $.75^{*}$ & .07 & $57 \%$ \\
\hline $\begin{array}{l}\text { 2. I often skim things I read in hard copy to get } \\
\text { the gist of them }\end{array}$ & $.60 *$ & .08 & $37 \%$ \\
\hline $\begin{array}{l}\text { 3. I can easily stop reading something if I don't } \\
\text { find it worth my while }\end{array}$ & $.41 *$ & $.20^{*}$ & $20 \%$ \\
\hline $\begin{array}{l}\text { 4. I feel compelled to read things that are in the } \\
\text { same series as something I've enjoyed }\end{array}$ & .07 & $.58 *$ & $34 \%$ \\
\hline $\begin{array}{l}\text { 5. I feel compelled to finish everything I begin } \\
\text { reading }\end{array}$ & $.24^{*}$ & $.53 *$ & $34 \%$ \\
\hline $\begin{array}{l}\text { 6. I often think about what I've been reading } \\
\text { even when I'm not actively reading it }\end{array}$ & .06 & $.53 *$ & $28 \%$ \\
\hline 7. I enjoy rereading things I've read before & .10 & $.46^{*}$ & $22 \%$ \\
\hline $\begin{array}{l}\text { 8. I like to have more than one thing to read } \\
\text { "on the go" at a time }\end{array}$ & & & \\
\hline
\end{tabular}

Note. *loading significant at $p<.05$ level. ${ }^{\text {a }}$ Item excluded from final EFA solution. 
Table 6. Correlations between PoLR subscales, measures of verbal ability and print exposure, and controls

1.

2.

3.

4.

5.

7.

9.

Reading Motivations

1. F1 "Reading for Enjoyment"

2. F2 "Reading to Grow"

3. F3 "Reading Due to the Judgement or Attention of Others"

\section{$-$}

$.56^{*}$

$[.37, .64]$

$[-.10, .13]$

$.36^{*}$

Reading Obstacles

4. F1 "Circumstances Prevent

Otherwise Enjoyable Reading"

5. F2 "Do not Enjoy Reading"

6. F3 "Reading is not Socially Valued"

Reading Attitudes

7. F1 "Reading is Part of my SelfConcept"

Reading Interests

8. F1 "Surface Interests"

Verbal Abilities

10. Sentence Completion task

11. Synonyms task

12. Analogy task

Print Exposure

13. ART Fiction

14. ART Nonfiction

15. ART Foils

16. Gender

17. Age
9. F2 "Engrained Interests"

$\begin{array}{ccc}-.20^{*} & -.15^{*} & .06 \\ {[-.29,-.06]} & {[-.26,-.02]} & {[-.07, .16]} \\ -.76^{*} & -.44^{*} & .02 \\ {[-.84,-.58]} & {[-.56,-.26]} & {[-.11, .12]} \\ -.17^{*} & -.04 & .28^{*} \\ {[-.27,-.01]} & {[-.17, .09]} & {[.09, .34]}\end{array}$

$.61^{*}$

$[.33, .57]$

$.44 *$
$[.20, .45]$

.04
$[-.07, .12]$

$.20 *$

$[.08, .46]$

$.54 *$

$[.31, .56]$

.33*

[.98, 2.25]

.34*

$[2.09,4.61]$

$.25^{*}$
$.25,1.00]$

.14
$-02,39]$

$[-.02, .39]$

$[.11, .36]$

$-.01$

$[-.20, .17]$

$[-.06, .14]$

.07

$[-.31, .87]$

.09

$[-.37,2.16]$

.07

$[-.14, .47]$

$-.07$

$[-.76, .41]$

$[-1.65, .73]$

$-.04$

$[-.36, .24]$

26

$.26^{*}$
$[1.12,2.87]$

.11

$[-.09, .81]$

.05

$[-.12, .29]$

$.37 *$
$[.11, .23]$

$-.04$

$[-.58, .30]$

$[-.37, .51]$
$22 *$

$[.72,2.72]$

$.18^{*}$

$[.26, .96]$

.09
$-.03, .34$

$[-.03, .34]$

.13
$-.002, .13$

$.14^{*}$
$[.19, .99]$

$[.19, .99]$
$.53^{*}$
$[.34, .58]$

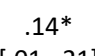

$[.01, .21]$

$.33^{*}$

$-.16^{*}$

$[-.21,-.02]$

$-.60^{*}$
$[-.57,-.33]$

$-.15 *$

$[-.21,-.001]$

$-.21 *-.26^{*}-07$

$[-.52,-.10]$

$-.06$

$[-.14, .05]$

$-.43^{*}$

$[-.47,-.23]$

$[-.24, .06]$

$-.07$

$[-.15, .04]$

.11

$-.32 *$

$[-2.18,-.88]$

$-.17^{*}$

$[-1.27,-.17]$

$.05 \quad-.36 *$

$[-.78,1.72]$

[-4.99, -2.30]

$-.14^{*}$

$-.05$

$-.32 *$
$[-1.20,-.48$

$[-2.23, .02]$

$-.17^{*}$

$[-.68,-.05]$

$-.03$

$-.03-.29 *$

$[-1.16, .76]$

$[-3.25,-1.30]$

$-.06$

$\begin{array}{ll}-.05 & -.09\end{array}$

$[-.63, .21]$

$[-.81, .17]$

$\begin{array}{cc}-.11 & -.07 \\ {[-.44, .06]} & {[-.42, .08]}\end{array}$

$[-.42, .08]$

$[-.01, .09]$

$-.35^{*}$
$-.22,-.10]$

$.12 *$

$[.03, .86]$

.02

$[-.42, .55]$

$[.03, .86]$

$[-1.27, .56]$

-.01
$[-.47, .51]$

.06

$[-.10, .32]$

$-.21 *$
$[-.15,-.03]$

-.08
$[-.70, .10]$

Note. $N=200 . \mathrm{F}=$ Factor. Values in brackets are bias-corrected bootstrapped $95 \%$ confidence intervals. ${ }^{*}$ statistically significant correlation.
, .37]

$\begin{array}{cc}.41^{*} & .17^{*} \\ {[.17, .36]} & {[.04, .37]}\end{array}$

$\begin{array}{ccc}.37^{*} & .09 & .30^{*} \\ {[.95,1.87]} & {[-.32,1.59]} & {[.68,1.83]} \\ .38^{*} & .08 & .27^{*} \\ {[2.04,4.10]} & {[-.64,3.21]} & {[1.22,3.55]} \\ .27^{*} & .04 & .18^{*} \\ {[.28, .84]} & {[-.30, .74]} & {[.06, .74]}\end{array}$

$.30^{*}$

$1.12,2.72] \quad .10$

$.08 \quad .04$

$[-.48, .95]$

$[.99,2.80]$

.11

$[-.06, .75]$

$[-.16, .17] \quad[-.04, .74]$

$.17^{*}$
$[.06, .46]$

$.38 * \quad .11$

$[.08, .18]$

$[-.02, .16]$

$.22 *$

$[.04, .14]$

-.06
$[-.67, .22]$

$[-1.21, .18]$ 
Table 6 (continued)

10.

11.

12.

13.

14.

15.

16.

17.

Reading Motivations

1. F1 "Reading for Enjoyment"

2. F2 "Reading to Grow"

3. F3 "Reading Due to the Judgement or Attention of Others"

Reading Obstacles

4. F1 "Circumstances Prevent

Otherwise Enjoyable Reading"

5. F2 "Do not Enjoy Reading"

6. F3 "Reading is not Socially Valued"

\section{Reading Attitudes}

7. F1 "Reading is Part of my SelfConcept"

Reading Interests

8. F1 "Surface Interests"

9. F2 "Engrained Interests"

Verbal Abilities

10. Sentence Completion task

11. Synonyms task

$.79 *$

12. Analogy task

[33.61, 48.22]

$.61^{*}$

$[6.09,9.77]$

$.62^{*}$

[13.38, 21.06]

Print Exposure

13. ART Fiction

14. ART Nonfiction

15. ART Foils

16. Gender

$.23^{*}$

$[4.25,14,18]$

$.25 *$

$\begin{array}{ccc}.12 & .16^{*} & .03 \\ {[-.06,4.53]} & {[.54,11.33]} & {[-.97,1.69]}\end{array}$

$[10.63,33.02]$

.10

$[-.06$

$-.07$

$-.14^{*}$

$.67^{*}$
$[11.33,28.95]$

$[-1.61, .56] \quad[-3.54,1.07] \quad[-1.40, .01]$

$[-. .06, .19]$

$-.05$

-.12
$[-.34, .02]$

$.62 *$

$.64^{*}$

$[4.80,15.48] \quad[2.20,6.87]$

$.19 *$

$[-1.04, .35]$

$[.24,1.13]$

$[-.22, .22]$

$<.01$

17. Age

$\begin{array}{cc}.25^{*} & .05 \\ {[3.77,18.60]} & {[-.94,2.02]}\end{array}$

$\begin{array}{ccc}.11 & .13^{*} & .01 \\ {[-.28,7.34]} & {[.03,4.40]} & {[-.71, .92}\end{array}$

$.13^{*}$
$[.03,4.40]$

$[-.12, .11]$

$-.09$

Note. $N=200$. Values in brackets are bias-corrected bootstrapped 95\% confidence intervals. ${ }^{*}$ statistically significant correlation. 
Table 7

Model fit indices for models for Reading Motivations, Obstacles, Attitudes, and Interests

\begin{tabular}{lccccccc}
\hline \multicolumn{1}{c}{ Model } & $\chi^{2}$ & $d f$ & $p$ & CFI & TLI & RMSEA & SRMR \\
\hline Reading Motivations & 208.23 & 175 & .04 & .98 & .97 & .03 & .04 \\
Reading Obstacles & 210.83 & 155 & $<.01$ & .97 & .96 & .04 & .04 \\
Reading Attitudes & 84.30 & 58 & .01 & .97 & .95 & .05 & .05 \\
Reading Interests & 74.63 & 61 & .11 & .98 & .97 & .03 & .05 \\
\hline
\end{tabular}

Note. Models are depicted in Figures 1-4. 


\section{Reading Motivations}

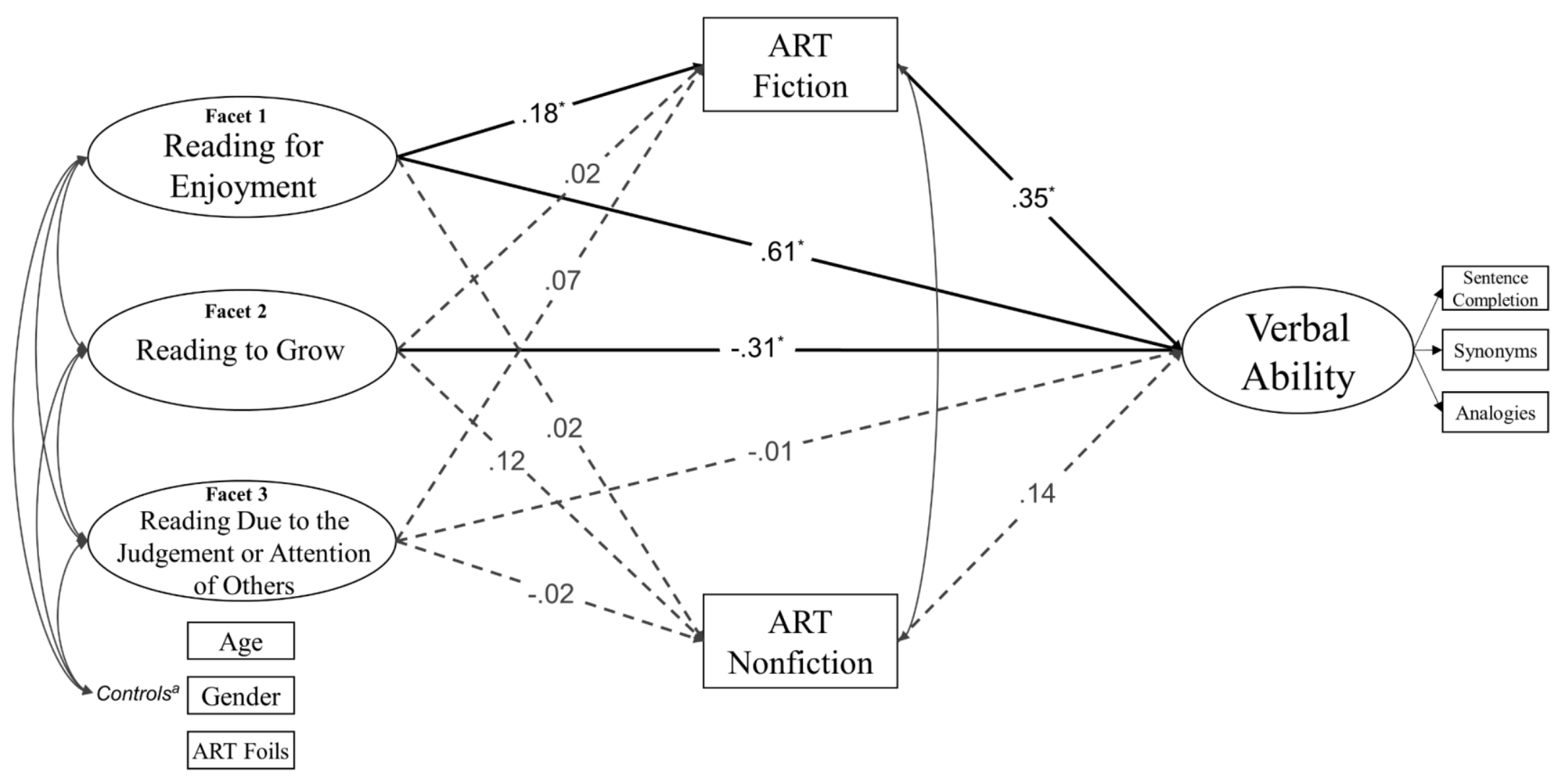

Figure 1. Structural path model for the reading motivations subscale. Significant paths are represented by solid lines $\left({ }^{*} p<.05\right)$.

${ }^{\mathrm{a}}$ Control paths are not depicted (Verbal ability, ART Fiction, and ART Nonfiction were each regressed on controls of Age, Gender, and ART Foils). 


\section{Reading Obstacles}

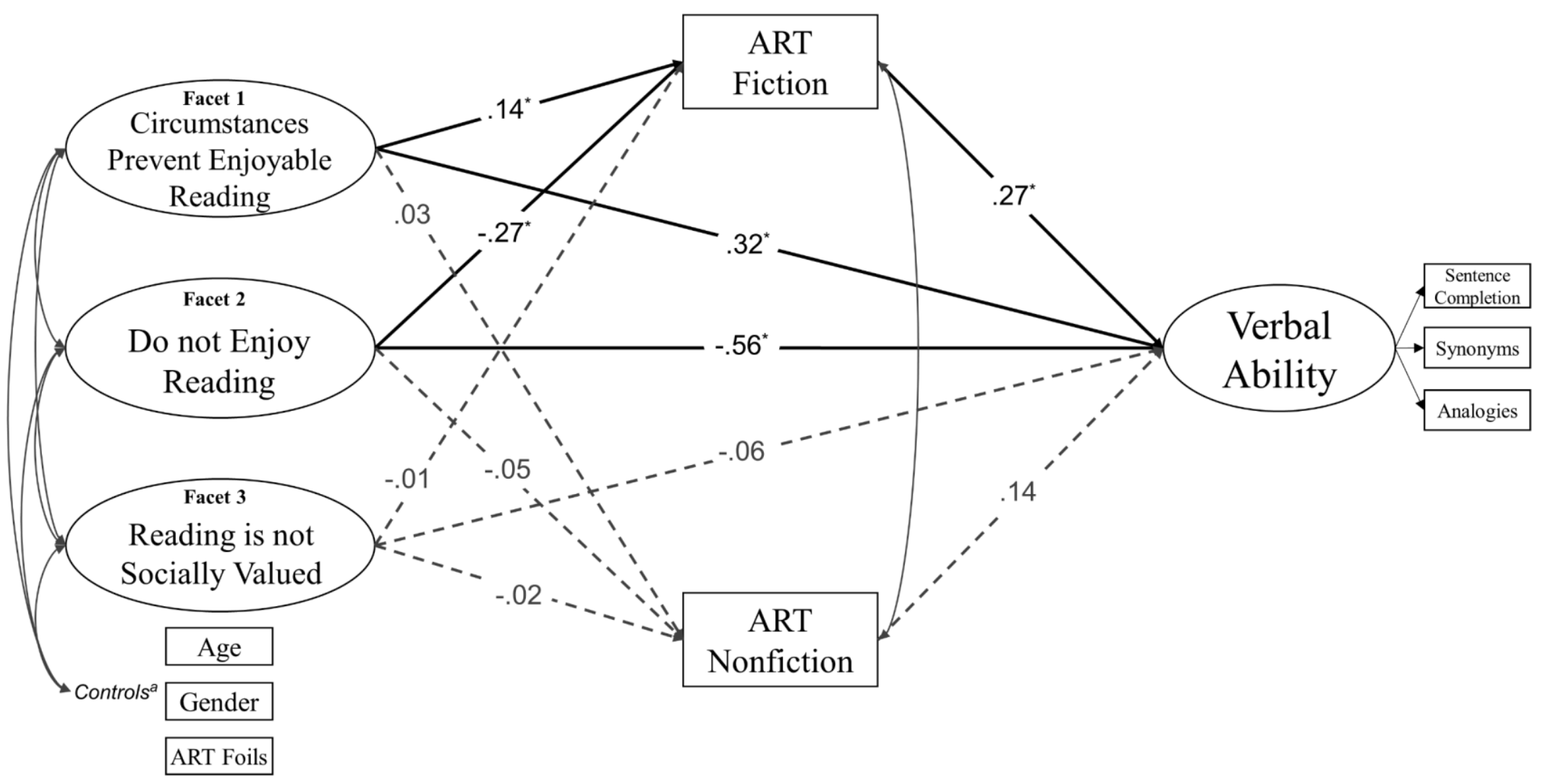

Figure 2. Structural path model for the reading obstacles subscale. Significant paths are represented by solid lines $\left({ }^{*} p<.05\right)$.

${ }^{\mathrm{a}}$ Control paths are not depicted (Verbal ability, ART Fiction, and ART Nonfiction were each regressed on controls of Age, Gender, and ART Foils). 


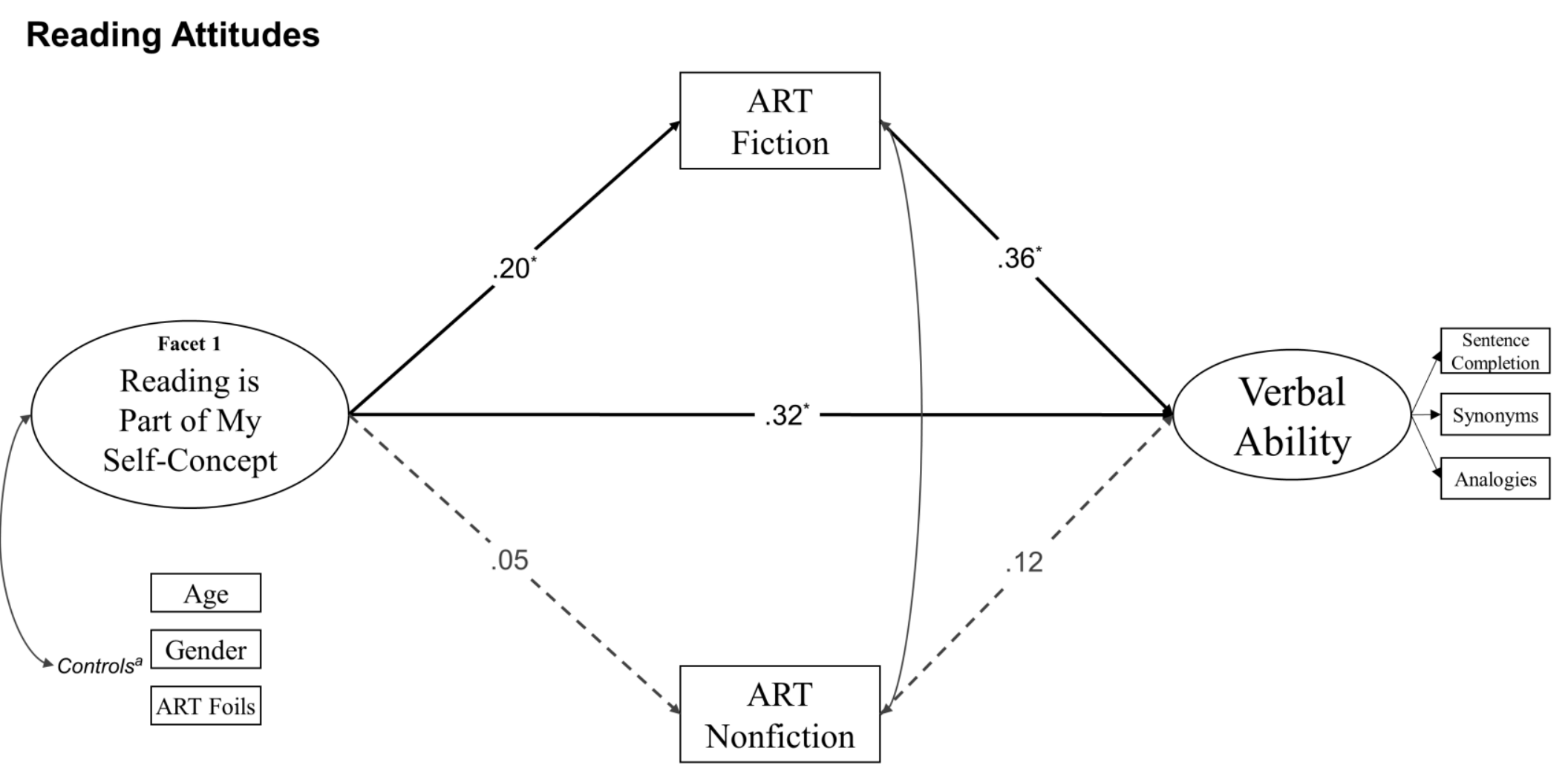

Figure 3. Structural path model for the reading attitudes subscale. Significant paths are represented by solid lines $\left({ }^{*} p<.05\right)$.

${ }^{\mathrm{a}}$ Control paths are not depicted (Verbal ability, ART Fiction, and ART Nonfiction were each regressed on controls of Age, Gender, and ART Foils). 


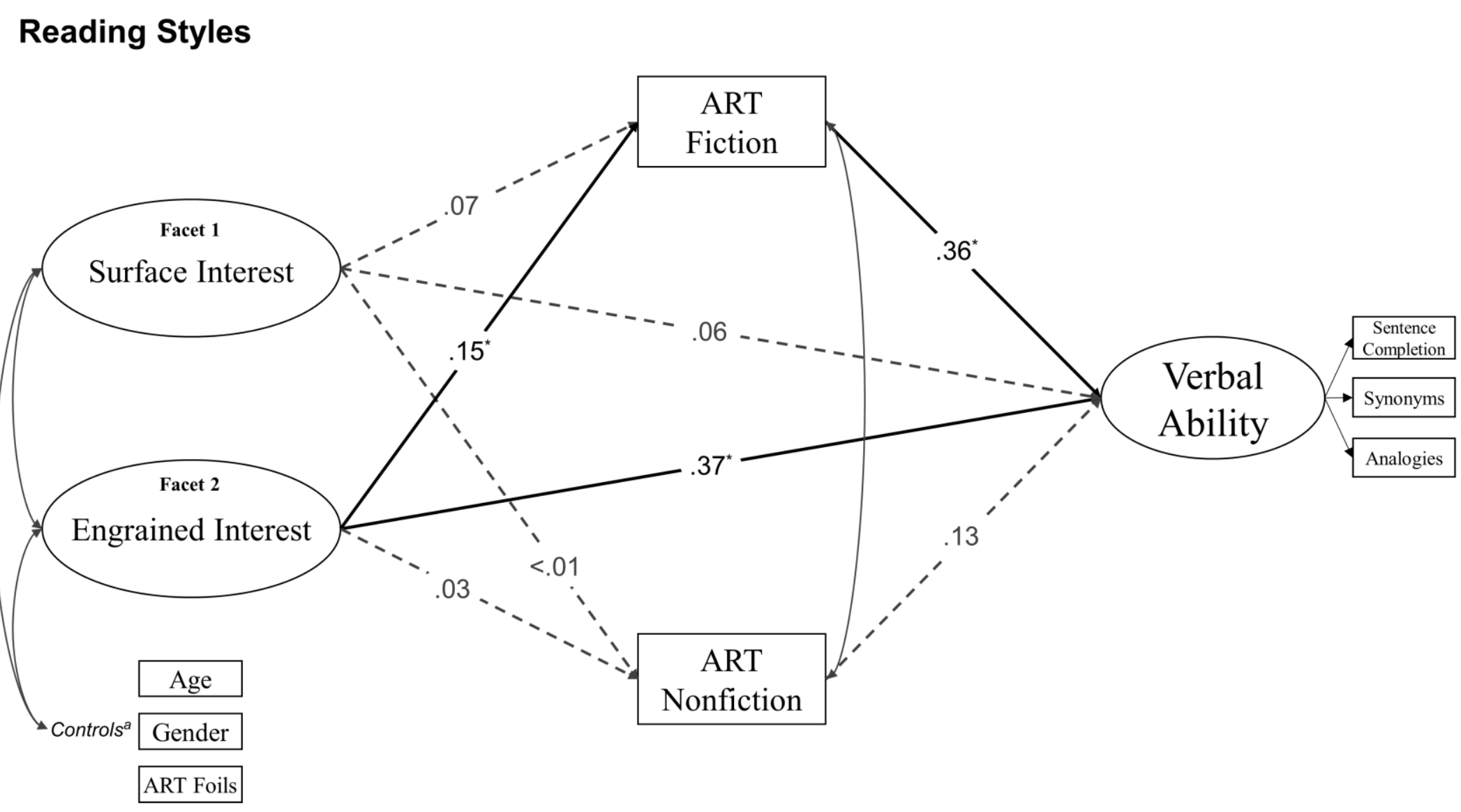

Figure 4. Structural path model for the reading interests subscale. Significant paths are represented by solid lines $\left({ }^{*} p<.05\right)$.

${ }^{\mathrm{a}}$ Control paths are not depicted (Verbal ability, ART Fiction, and ART Nonfiction were each regressed on controls of Age, Gender, and ART Foils). 